\title{
CD40 Employs p38 MAP Kinase in IgE Isotype Switching
}

\author{
Kevin Brady,*,1 Stephen Fitzgerald, ${ }^{*, 1}$ Sigurdur Ingvarsson,† Carl A. K. Borrebaeck,† \\ and Paul N. Moynagh*,2 \\ *Department of Pharmacol ogy, Conway Institute of Biomol ecular and Biomedical Research, University College Dublin, \\ Foster Avenue, Blackrock, Co. Dublin, I reland; and †Department of I mmunotechnol ogy, Lund University, Sweden
}

IgE switching requires the prior induction of $\mathrm{C}_{\epsilon}$ germline transcripts which is mediated by the concerted binding of STAT-6 and NF $\kappa$ B to the C $\epsilon$ promoter. These transcription factors are regulated by IL -4 and CD40, respectively. However the latter can effect other signaling pathways and the present study explores the role of 38 MAPK in induction of $C \epsilon$ germline transcripts. CD40 and IL -4, both alone and in synergy, were initially shown to activate the $\mathrm{C} \epsilon$ promoter in a B cell lymphoma cell line. Under the same conditions CD40 caused activation of p38 MAPK, whereas IL-4 was ineffective. The p38 MAPK inhibitor, SB203580, and a dominant negative form of p38 MAPK decreased the CD40 activation of the $C \epsilon$ promoter by reducing the ability of CD40 to increase the transactivation potential of NF $\kappa$ B. This study suggests that p38 MAPK is crucially important in mediating CD40 activation of NF $\kappa$ B which acts to induce $C \epsilon$ germline transcripts, ultimately facilitating IgE switching. $\odot 2001$ Academic Press

Key Words: CD40; I gE ; i sotype switching; allergy; p38 MAP kinase; NF $\kappa$ B.

IgE is a central player in the generation of allergic diseases and thus the molecular mechanisms underlying IgE synthesis have become an area of intense interest (reviewed in 1). In order for a B lymphocyte to produce IgE, it needs to undergo a process known as isotype switching. This phenomenon involves the recombination of the VDJ gene region to a different heavy chain $C\left(C_{H}\right)$ gene which will thus encode for another heavy chain isotype with different effector functions but with the same antigen-binding specificity (2). Such recombination takes place between the $5^{\prime}$ intronic segment, known as the switch (S) region, of the $\mathrm{C}_{\mu}$ gene and the corresponding $\mathrm{S}$ region of the appropriate $\mathrm{C}_{H}$ gene (3). In the case of switching to IgE,

\footnotetext{
${ }^{1}$ These authors contributed equally to the work.

${ }^{2}$ To whom correspondence should be addressed. Fax: +353-12692749. E-mail: P.Moynagh@ucd.ie.
}

recombination results in the formation of a $\mathrm{S} \mu / \mathrm{S} \epsilon$ junction, with deletion of the intervening DNA. However a necessary pre-requisite for this deletional recombination is the prior transcription of the $C \epsilon$ gene which starts at the $I \epsilon$ exon, upstream of the $S \epsilon$ region, and continues through the $S$ region and $C \epsilon$ gene (4). The $S$ region is removed by splicing, resulting in the joining of the $I \epsilon$ exon and $C \epsilon$ region which together form a germline sterile transcript (5). The induction of these $\mathrm{C}_{\epsilon}$ germline transcripts is a determining step in isotype switching to IgE since transcription through the $\mathrm{C} \epsilon$ gene segment makes that region accessible to switch recombination (6). The induction of $\mathrm{C} \epsilon$ germline transcripts is regulated by a promoter region, upstream of the $\epsilon$ exon, and it is activated by the concerted binding of the transcription factors STAT- 6 and NF $\kappa \mathrm{B}$ (7-9). I L-4 regulates the activation of STAT- 6 and the importance of this pathway in IgE synthesis is emphasised by the lack of IgE switching in mice deficient for STAT-6 (10). The engagement of the B cell transmembrane protein CD40 by its cognate ligand is sufficient to cause activation of NF- $\kappa \mathrm{B}(8,11)$ and this synergises with STAT- 6 to activate the $C \epsilon$ promoter $(8,9)$. The crucial contribution of CD40 activation of NF- $\kappa \mathrm{B}$ to I gE synthesis is reinforced by the observation that CD40 ligand-deficient patients (12), CD40 deficient mice (13) and $\mathrm{NF}-\kappa \mathrm{B}$ deficient mice (14) are all defective in IgE isotype switching and lack serum IgE. However the activation of NF- $\mathrm{B}$ may not be the sole contributory pathway to mediating IgE switching in response to CD40. The engagement of the latter has also been shown to activate a plethora of intracellular signaling molecules including protein tyrosine kinases and $\mathrm{PI}-3$ kinase (15). In addition much recent interest has focussed on the ability of CD40 to activate the mitogenactivated protein kinases (MAPKs), especially the c-jun $\mathrm{N}$-terminal kinase/stress-activated protein kinase (J NK/SAPK) $(16,17)$ and the p38 MAPK $(18,19)$. While the functional consequences of CD40 activation of these MAPKs remain to be fully resolved a recent report has demonstrated a role for p38 in mediating 


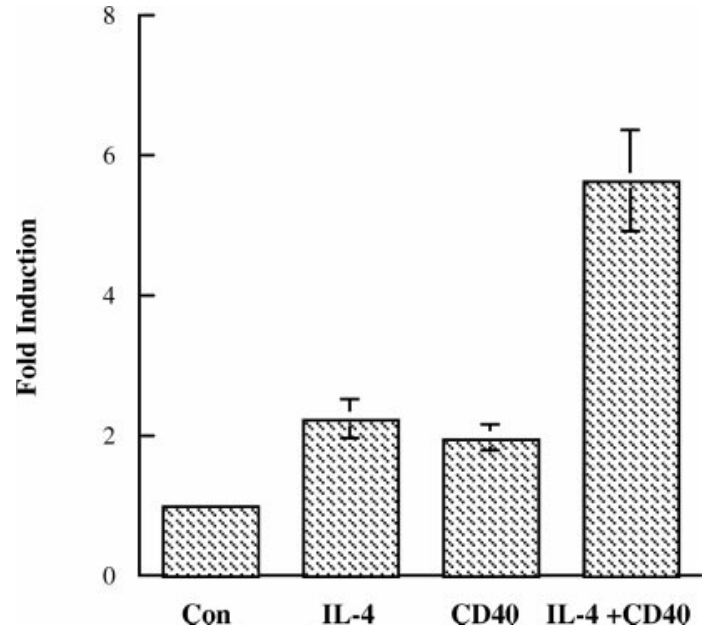

FIG. 1. Activation of $C \epsilon$ promoter by IL-4 and engagement of CD40 in BJ AB B cells. BJ AB cells $\left(1 \times 10^{7}\right.$ cells) were electroporated with $\epsilon$-luc $(10 \mu \mathrm{g})$, a plasmid encoding a luciferase reporter gene regulated by the $\mathrm{C} \epsilon$ promoter. Electroporated cells were subsequently treated for $24 \mathrm{~h}$ in the absence (Con) and presence of IL-4 $(100 \mathrm{U} / \mathrm{ml})$ and/or an anti-CD40 antibody $(500 \mathrm{ng} / \mathrm{ml})$ adsorbed onto CD32-transfected fibroblasts. Cell extracts were measured for luciferase activity and the results are expressed as fold induction of Iuciferase relative to cells which were treated in the absence of IL-1 and anti-CD40 antibody. The data represent mean +/- SEM of four independent experiments.

the CD40-induced proliferation of B cells and its induction of genes such as ICAM-1 (20). Interestingly, the same report also described a lack of involvement of p38 in mediating the CD40 induction of a wide range of other proteins including CD40 itself, CD95/F as, cl AP2, TRAF 1, TRAF4, and DR3 and thus concluded that CD40 induces gene expression via both p38 MAPKdependent and independent pathways. This prompted the present investigation into whether p38 is employed by CD40 in mediating one of its most important biological effects in B cells, namely its induction of $\mathrm{C} \epsilon$ germline transcripts which acts as the key determining step in I gE isotype switching.

The study exploited the specific cell-permeable p38 MAPK inhibitor SB203580 (21) and a dominant negative form of p38 MAPK to show that p38 is crucially involved in mediating the CD40 activation of the C $\epsilon$ promoter which regulates induction of $\mathrm{C} \epsilon$ germline transcripts. The results also suggest that p38 contributes to the activation of the promoter by increasing the transactivation potential of $\mathrm{NF}-\kappa \mathrm{B}$. The study thus concludes that p38 MAPK is a crucial player in IgE isotype switching and may represent a valuable target in controlling unwanted IgE synthesis in allergic reactions.

\section{MATERIALS AND METHODS}

Materials. RPMI 1640 and FCS were from Life Technologies, Inc. (Paisley, UK). Glutamine, streptomycin, and HAT medium (100 $\mu \mathrm{M}$ hypoxanthine, $0.4 \mu \mathrm{M}$ aminopterin, $16 \mu \mathrm{M}$ thymidine) werefrom Sigma (Poole, UK). IL-4 was from R \& D (Oxon, UK). Luciferase substrate and lysis buffer were from Promega Corp. (Madison, WI). The PhosphoPlus p38 MAP Kinase antibody kit was from New England Biolabs (Beverly, MA). SB203580 was from CalbiochemNovabiochem Ltd. (Nottingham, UK). The EBV negative human B cell lymphoma cell line was a gift from Dr. D. Walls, Dublin City University, I reland. CD32-transfected fibroblasts (ATCC No. CRL10680) and the anti-CD40 antibody are previously described (22). The $\epsilon$-luciferase reporter plasmid ( $\epsilon$-luc) consists of the germline $\mathrm{C}_{e}$ promoter (the region $-162 /+53$ relative to the first initiation site for germline $\epsilon$-transcripts) ligated upstream of the luciferase reporter gene and was a gift from Professor J. Stavnezer (University of Massachusetts Medical School, MA). The NF $\kappa$ B-luciferase reporter plasmid ( $\kappa \mathrm{B}-\mathrm{luc}$ ) consists of five copies of the NF $\kappa$ B consensus site cloned into the luciferase reporter construct pGL3-Basic (Promega Corporation). The plasmid encoding dominant negative p38 MAPK was a gift from Professor R. J . Davis (University of Massachusetts Medical Center, MA) and has been described previously (23). PEGFP-N 1 (in which EGFP stands for enhanced green fluorescent protein) was from Clontech Laboratories (Palo Alto, CA).

Cell culture Human BJ AB cells were cultured in RPMI 1640 medium supplemented with $10 \%$ FCS, 2 mM L-glutamine, $100 \mathrm{U} / \mathrm{ml}$ penicillin, and $100 \mu \mathrm{g} / \mathrm{ml}$ streptomycin. CD32-transfected fibroblasts (ATCC No. CRL-10680) were cultured in RPMI 1640 supplemented

Con IL-4 CD40 IL-4

A
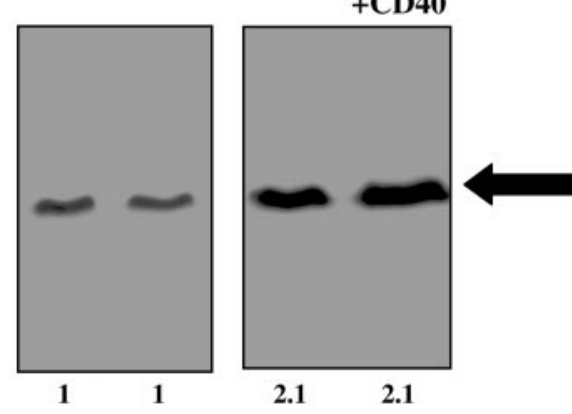

Phospho
P38
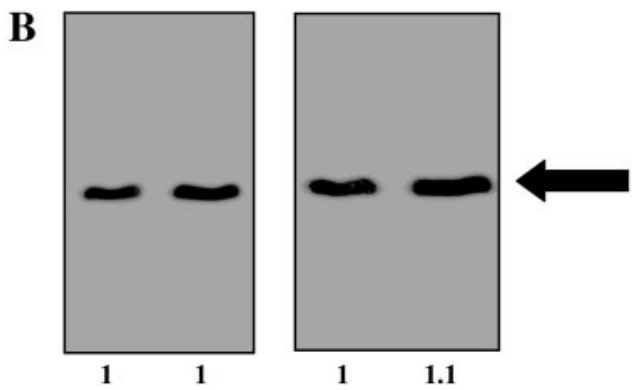

Total

P38

FIG. 2. Engagement of CD40 activates p38 MAPK in BJ AB cells. $B J A B$ cells $\left(1 \times 10^{7}\right.$ cells) were treated for $30 \mathrm{~min}$ in the absence and presence of IL-4 (100 U/ml) and/or an anti-CD40 antibody (500 $\mathrm{ng} / \mathrm{ml}$ ) adsorbed onto CD32-transfected fibroblasts. Cell lysates were prepared and analysed by Western immunoblotting for levels of $(A)$ phosphorylated p38 MAPK and (B) total p38 MAPK using the PhosphoPlus p38 MAP kinase antibody kit (New England Biolabs). Immunoreactivity was visualised by enhanced chemiluminesence and band intensity quantitated by densitometric scanning on a Molecular Dynamics 300 S computing densitometer (Sunnyvale, CA) using I mageQuant V3.0 software. The numbers under each lane represent the band intensity relative to the intensity of the band in cells which had been treated in the absence of IL-4 and anti-CD40. 
A

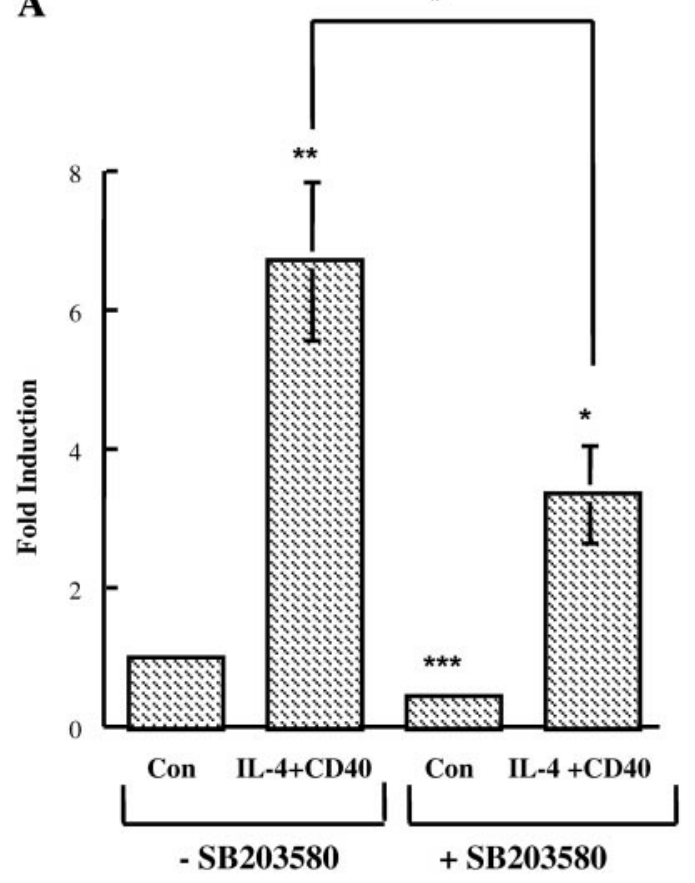

B

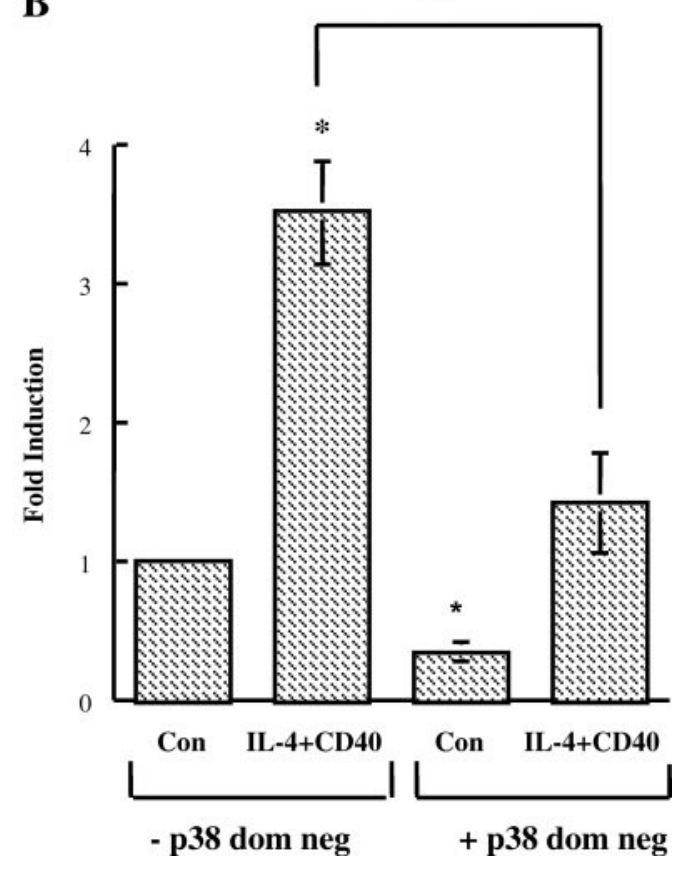

FIG. 3. SB203580 and dominant negative p38 MAPK inhibit CD40 activation of $C \epsilon$ promoter. (A) BJ AB cells $\left(1 \times 10^{7}\right.$ cells) were electroporated with $\epsilon$-luc $(10 \mu \mathrm{g})$, a plasmid encoding a luciferase reporter gene regulated by the $\mathrm{C} \epsilon$ promoter. Electroporated cells were treated with and without SB203580 (10 $\mu \mathrm{M})$ for $1 \mathrm{~h}$ and subsequently stimulated for $24 \mathrm{~h}$ in the absence (Con) and presence (I L-4+CD40) of IL-4 (100 U/ml) and anti-CD40 antibody $(500 \mathrm{ng} / \mathrm{ml})$. (B) BJ AB cells $\left(1 \times 10^{7}\right.$ cells) were cotransfected by electroporation with an empty expression vector (15 $\mu \mathrm{g}$ of DNA) or the same amount of expression vector encoding dominant negative p38 MAPK, with $10 \%$ FCS, $2 \mathrm{mM}$ L-glutamine, $100 \mathrm{U} / \mathrm{ml}$ penicillin, $100 \mu \mathrm{g} / \mathrm{ml}$ streptomycin, and HAT medium supplement. Both cell types were grown in a humidified atmosphere of $5 \% \mathrm{CO}_{2}$ at $37^{\circ} \mathrm{C}$.

Transfection of $B J A B$ cells and assay of expression of luciferase reporter genes. Aliquots $(250 \mu \mathrm{l})$ of $\mathrm{BJ} A B$ cells $\left(4 \times 10^{7}\right.$ cells $\left./ \mathrm{ml}\right)$ were electroporated $(220 \mathrm{~V}, 960 \mu \mathrm{F})$ with $\epsilon$-luc $(10 \mu \mathrm{g})$ or $\kappa \mathrm{B}$-luc (5 $\mu \mathrm{g})$ in RPMI 1640 medium supplemented with 10\% FCS, 2 mM L-glutamine, $100 \mathrm{U} / \mathrm{ml}$ penicillin, and $100 \mu \mathrm{g} / \mathrm{ml}$ streptomycin by means of a Bio-Rad Gene Pulser equipped with a capacitance extender (Bio-Rad, Hercules, CA). In some experiments BJ AB cells were cotransfected with $15 \mu \mathrm{g}$ of the expression vector encoding dominant negative p38 MAPK, $5 \mu \mathrm{g}$ of pEGFP-N 1 and $\epsilon$-luc $(10 \mu \mathrm{g})$ or $\kappa \mathrm{B}$-luc $(5 \mu \mathrm{g})$. The el ectroporated cells were subsequently added to fresh medium ( $5 \mathrm{ml}$ ) and allowed to recover for $24 \mathrm{~h}$ in a humidified atmosphere of $5 \% \mathrm{CO}_{2}$ at $37^{\circ} \mathrm{C}$. Aliquots $(2.5 \mathrm{ml})$ of recovered cells were incubated in the absence or presence of SB203580 (10 $\mu \mathrm{M})$ for $1 \mathrm{~h}$ prior to stimulation with or without anti-CD40 monoclonal antibody $(500 \mathrm{ng} / \mathrm{ml})$ and recombinant human I L-4 (100 U/ml) for $5 \mathrm{~min}$ at room temperature. Cells were subsequently mixed with aliquots ( $750 \mu \mathrm{l} ; 4 \times 10^{5}$ cells $/ \mathrm{ml}$ ) of CD32-transfected fibroblasts and aliquots $(250 \mu \mathrm{l})$ of the mixed BJ AB/fibroblast suspension then seeded into 96-well plates and incubated at $37^{\circ} \mathrm{C}$ for a further $24 \mathrm{~h}$. Cells extracts were then generated and measured for luciferase activity using the Luciferase Assay System with Reporter Lysis buffer from Promega Corporation. Transfection efficiency was measured by counting the number of cells expressing the EGFP fluorescent protein using flow cytometry as described previously (24).

Western bl ot analysis of p38 phosphorylation. Aliquots $(2.5 \mathrm{ml})$ of untransfected BJ AB cells $\left(4 \times 10^{6}\right.$ cell $\left.\mathrm{s} / \mathrm{ml}\right)$ were stimulated for 30 min in the absence or presence of anti-CD40 monoclonal antibody and IL-4, as described above. Stimulation was terminated by centrifuging the cells at $1450 \mathrm{~g}$ for $5 \mathrm{~min}$ and washing the cell pellet once in PBS $(1 \mathrm{ml})$. The cells were then lysed in SDS-PAGE sample buffer $(100 \mu$ l) $(50$ mM Tris-HCl buffer, pH 6.8 containing 2\% (w/v) SDS, $10 \%$ glycerol, 1\% (v/v) 2-mercaptoethanol and 0.1\% bromophenol blue). The lysates were sonicated for $10 \mathrm{~s}$ to reduce sample viscosity and then heated to $90^{\circ} \mathrm{C}$ for $5 \mathrm{~min}$. Lysates were cleared of particulate material by centrifugation at $20,000 \mathrm{~g}$ for $5 \mathrm{~min}$. Aliqouts $(25 \mu \mathrm{l})$ of the clear supernatants were subjected to SDS-PAGE on $12 \%$ polyacrylamide slab gels and the separated proteins electrophoretically transferred from the gels to nitrocellulose. The nitrocellulose was then probed for levels of phosphorylated and total p38 using the PhosphoPlus p38 MAP Kinase (Thr180/Tyr182) antibody kit as recommended by the manufacturers (New England Biolabs). I mmunoreactivity was visualised by enhanced chemiluminesence. Densitometric scanning of enhanced chemiluminescence blots was performed on a Molecular Dynamics 3005 computing densitometer (Sunnyvale, CA) using I mageQuant V3.0 software.

Statistical analysis. Significance was evaluated by Student's t test for unpaired data.

\section{RESULTS AND DISCUSSION}

The overall objective of this study was to explore the potential role of p38 in IgE isotype switching in B

together with a pEGFP-N1 plasmid encoding constitutively expressed EGFP (5 $\mu \mathrm{g}$ of DNA) and $\epsilon$-luc $(10 \mu \mathrm{g})$. Electroporated cells were subsequently incubated for $24 \mathrm{~h}$ as above in the absence and presence of IL-4 and anti-CD40. All cell extracts were measured for luciferase activity and the results are expressed as fold induction of luciferase relative to control cells which were treated in the absence of IL-4 and anti-CD40 antibody. The data represent mean +/- SEM of four independent experiments. Significantly different $(* P<0.05$, $* * P<0.01, * * * P<0.001)$ when compared to control values. 
A
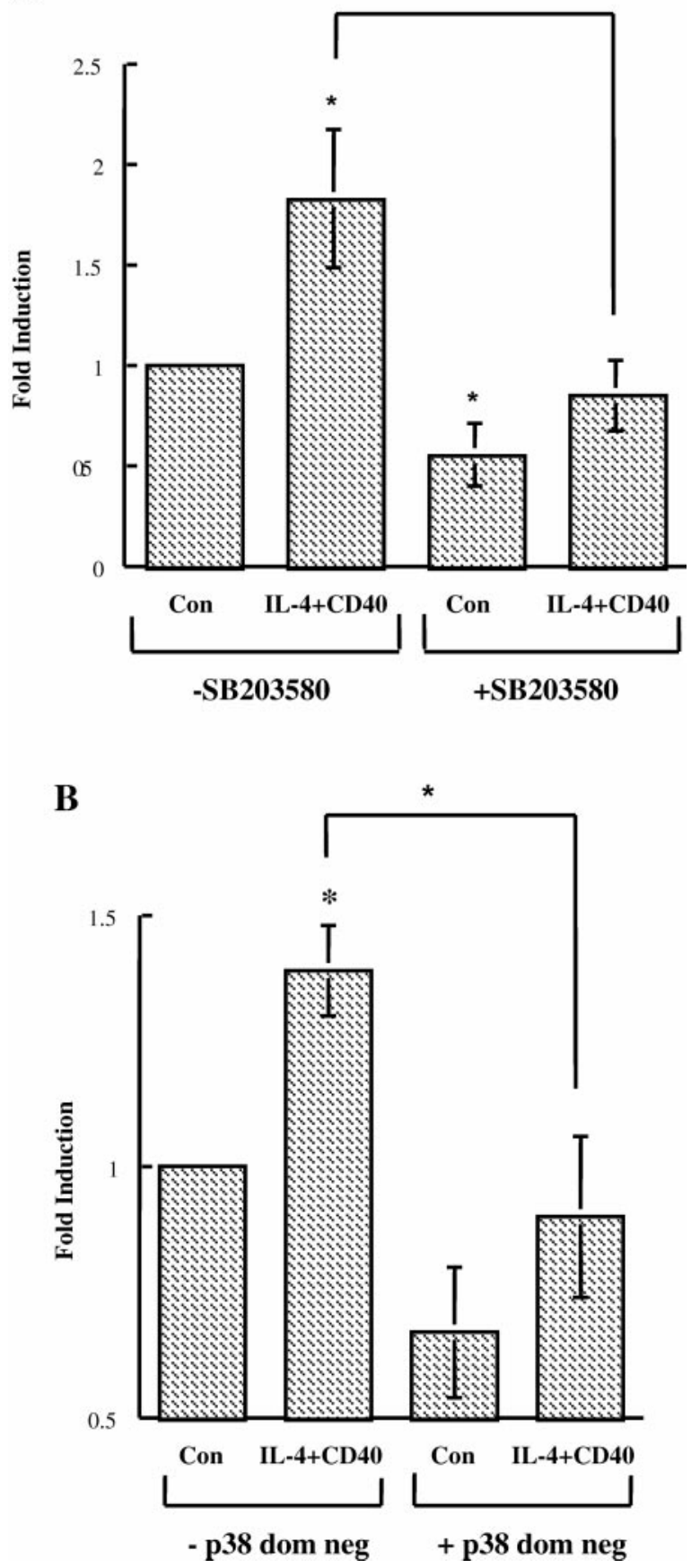

FIG. 4. SB203580 and dominant negative p38 MAPK inhibit CD40 induction of NF $\kappa$ B-regulated reporter gene. (A) BJ AB cells $\left(1 \times 10^{7}\right.$ cells) were electroporated with $\kappa$ B-luc $(5 \mu \mathrm{g})$, a plasmid encoding a luciferase reporter gene regulated by a promoter containing five copies of the NF $\kappa \mathrm{B}$ consensus site. Electroporated cells were treated with and without SB203580 $(10 \mu \mathrm{M})$ for $1 \mathrm{~h}$ and subsequently stimulated for $24 \mathrm{~h}$ in the absence (Con) and presence (IL$4+C D 40)$ of I L-4 (100 U/ml) and anti-CD40 antibody (500 ng/ml). (B) BJ AB cells $\left(1 \times 10^{7}\right.$ cells) were cotransfected by electroporation with an empty expression vector (15 $\mu \mathrm{g}$ of DNA) or the same amount of expression vector encoding dominant negative p38 MAPK, together with a pEGFP-N 1 plasmid encoding constitutively expressed EGFP (5 $\mu \mathrm{g}$ of DNA) and $\kappa \mathrm{B}$-luc $(5 \mu \mathrm{g})$. Electroporated cells were subsequently incubated for $24 \mathrm{~h}$ as above in the absence and presence of lymphocytes. Since the induction of $\mathrm{C} \epsilon$ germline transcripts is the key step in initiating IgE switching this prompted an investigation into the importance of p38 in regulating this induction process. However, it was necessary to initially establish a suitable model system for investigation. The EBV negative $B$ cell lymphoma $B J A B$ cell line was used as the model human $B$ cell system. The process of I gE switching requires the dual signals of IL-4 and activation of CD40 and this was achieved by treating the $B J A B$ cells with exogenous human recombinant IL -4 and an agonistic anti-CD40 antibody adsorbed onto CD32-trasfected fibroblasts. The latter has been shown to be an effective means of cross-linking and activating CD40 (22). BJ AB cells were initially examined for their responsiveness to stimulation by IL-4 and CD40 with respect to activation of the promoter controlling expression of the $\mathrm{C} \epsilon$ germline transcripts. The activity of the $\mathrm{C} \epsilon$ promoter was determined by measuring the expression of a transfected luciferase gene ligated downstream of the $\mathrm{C} \epsilon$ promoter ( $\epsilon$-luc) (8). BJ AB cells, in the absence of stimulation by IL -4 and CD40, displayed basal expression of luciferase and any induction above this level is displayed as fold induction. BJ AB cells showed some basal activation of the $\mathrm{C} \epsilon$ promoter but $\epsilon$-luc expression was increased approximately twofold by stimulating the cells alone with either IL-4 or CD40 (Fig. 1). The combination of both stimuli caused a synergistic sixfold induction of luciferase. Such synergistic activation of the $C \epsilon$ promoter by IL -4 and CD40 is consistent with a previous report (8) and is explained by the concerted binding of STAT- 6 and NF $-\kappa$ B to the $C \epsilon$ promoter (7-9). These findings further validate a previous report which promoted the BJ AB cell line as a valuable model system for exploring the regulation of expression of germline $\mathrm{C} \epsilon$ transcripts (25). Thus BJ AB cells and the $\epsilon$-luc reporter system were employed as a suitable paradigm to explore the role of p38 in mediating the induction of C $\epsilon$ germline transcripts in B cells. However prior to such an exploration it was necessary to show that CD40 could activate p38 in BJ AB cells.

$B J A B$ cells were stimulated in the presence and $a b-$ sence of IL-4 and agonistic anti-CD40 antibody and subsequently examined for activation of the p38 pathway. This was judged by probing the cells for immunoreactivity with an antibody which detects doubly phosphorylated threonine 180 and tyrosine 182 of p38 MAPK. Western immunoblotting demonstrated that cells in the absence of stimulation by IL-4 and CD40,

IL-4 and anti-CD40. All cell extracts were measured for luciferase activity and the results are expressed as fold induction of luciferase relative to control cells which were treated in the absence of IL-4 and anti-CD40 antibody. The data represent mean $+/-$ SEM of four independent experiments. Significantly different ( $* P<0.05)$ when compared to control values. 
contained a band representing a protein of $38 \mathrm{kDa}$ which reacted with the antibody indicative of some basal levels of phosphorylated p38 MAPK in BJ AB cells (Fig. 2A). The engagement of CD40 alone was sufficient to at least double the intensity of the band thus demonstrating that CD40 can activate the p38 MAPK pathway in BJ AB cells. The addition of IL-4 failed to affect the degree of basal or CD40 induced phosphorylation of p38 indicating that it does not contribute to the activation of the p38 MAPK pathway in $B$ cells. As control for the assay, all samples showed equivalent levels of total p38 as judged by Western immunoblotting analysis using control antibodies which recognise p38 irrespective of its phosphorylation status (Fig. 2B). The ability of CD40 engagement to activate the p38 MAPK pathway in B cells confirms similar previous findings (18-20). The lack of effect of IL-4 on p38 is not surprising since its primary role is to activate the transcription factor STAT- 6 via the unrelated J AK-3 kinase (26).

The demonstration that CD40 activates p38 in BJ AB cells allowed for the exploration of the contribution of this pathway to mediating CD40 induction of C $\epsilon$ germline transcripts. This was achieved by initially evaluating the inhibitory effects of SB203580, the p38 MAPK inhibitor, on the activity of the $\mathrm{C} \epsilon$ promoter, as judged by expression of the $\epsilon$-luc reporter gene (Fig. 3A). SB203580 reduced the basal expression of $\epsilon$-luc and inhibited by over $50 \%$ the ability of CD40 to induce $\epsilon$-luc. This indicates a key role for p38 in mediating the CD40 induction of $\mathrm{C} \epsilon$ germline transcripts, the prologue to IgE switching. This was further confirmed by probing the effect of cotransfected dominant negative p38 MAPK on the activity of the $\mathrm{C} \epsilon$ promoter (Fig. 3B). Like SB203580, dominant negative p38 MAPK markedly reduced the basal and CD40-induced expression of $\epsilon$-luc, confirming the crucial role of p38 MAPK in mediating the activation of the $\mathrm{C} \epsilon$ promoter by CD40. Dominant negative p38 MAPK had no effect on transfection efficiency since cells transfected with dominant negative p38 and control cells transfected with an empty expression vector displayed comparable transfection efficiencies of $12 \%$. The clear role of p38 in mediating the CD40 activation of the $\mathrm{C} \epsilon$ promoter prompted an investigation into the underlying mechanism. The unequivocal importance of $N F \kappa B$ in the CD40 signaling pathway leading to I gE swithing (8, 9, $11,14)$ coupled to recent reports describing a role for p38 in regulating the transactivation potential of $\mathrm{NF} \kappa \mathrm{B}(20,27)$ warranted an analysis of the involvement of p38 in modulating the activity of NF $\kappa B$ in the present experimental system.

The activity of NF $\kappa B$ in the BJ AB cells was determined by measuring the induction of a transfected $N F \kappa B$-regulated luciferase gene ( $\kappa$ B-luc) (Fig. 4). The stimulation of CD40 in BJ AB cells was sufficient to induce an approximate twofold induction of luciferase.
The pretreatment of cells with SB203580 dramatically reduced the ability of CD40 to induce $\kappa \mathrm{B}$-luc indicating an important role for p38 in mediating the CD40 activation of $\mathrm{NF} \kappa \mathrm{B}$ (Fig. 4A). This was further confirmed by the equally impressive inhibitory effects of cotransfected dominant negative p38 MAPK on the induction of $\kappa$ B-luc by CD40 (Fig. 4B). Since SB203580 fails to affect the ability of CD40 to effect nuclear transl ocation and DNA-binding of $\mathrm{NF} \kappa \mathrm{B}$ in $\mathrm{BJ} \mathrm{AB}$ cells (data not shown) these findings suggest that the CD40 activation of $\mathrm{p} 38$ facilitates increased NF $\kappa \mathrm{B}$ activity by improving its transactivation potential. This confirms a recent report which proposes a similar mechanism by which CD40 activates NF $\kappa$ B and thus induces B cell proliferation (20).

In summary, the present study thus proposes that CD40 activates p38 MAPK in B cells which in turn increases the ability of nuclear translocated $N F \kappa B$ to activate the $C \epsilon$ promoter and induce $C \epsilon$ germline transcripts. This ultimately promotes IgE isotype switching and thus p38 is a major player in facilitating IgE synthesis. Such findings promote p38 as a novel target to exploit in the development of new therapeutic re gimes to counter the production of I gE in allergy-based diseases.

\section{ACKNOWLEDGMENTS}

The work was supported by the European Commission 4th Frame work Biotechnology Programme (BIO4 CT96 0246), 5th Framework Biotechnology Programme (QLK3-CT-2000-00270), and Enterprise Ireland.

\section{REFERENCES}

1. Bacharier, L. B., J abara, H., and Geha, R. S. (1998) Molecular mechanisms of immunoglobulin E regulation. Int. Arch. Allergy Immunol. 115, 257-269.

2. Stavnezer, J . (1996) Antibody class switching. Adv. Immunol. 61, 79-146.

3. Muller, J. R., Giese, T., Henry, D. L., Mushinski, J. F., and Marcu, K. B. (1998) Generation of switch hybrid DNA between Ig heavy chain-mu and downstream switch regions in B Iymphocytes. J . Immunol. 161, 1354-1362.

4. Bottaro, A., Lansford, R., Xu, L., Zhang, J ., Rothman, P., and Alt, F. W. (1994) I region transcription (per se) promotes basal IgE class switch recombination but additional factors regulate the efficiency of the process. EMBO J . 13, 665- 674.

5. Gauchat, J -F., Lebman, D. A., Coffman, R. L., Gascan, H., and de Vries, J . E. (1990) Structure and expression of germline e transcripts in human B celss induced by interleukin-4 to switch to IgE production. J . Exp. Med. 172, 463- 473.

6. Snapper, C. M., Marcu, K. B., and Zelazowski, P. (1997) The immunoglobulin class switch: Beyond "accessibility." I mmunity 6, 217-223.

7. Delphin, S., and Stavnezer, J. (1995) Characterization of an interleukin-4 (IL-4) response region in the immunoglobulin heavy chain germline $\epsilon$ promoter: Regulation by NF-IL-4, a C/EBP family member and NF-кB/p50. J . Exp. Med. 181, 181192. 
8. Iciek, L., Delphin, S., and Stavnezer, J. (1997) CD40 Crosslinking induces I $\mathrm{g} \epsilon$ germline transcripts in B cells via activation of NF- $\kappa$ B. J . I mmunol. 158, 4769-4779.

9. Messner, B., Stutz, A. M., Albrecht, B., Peiritsch, S., and Woisetschlager, M. (1997) Cooperation of binding sites for STAT6 and $\mathrm{NF}-\kappa \mathrm{B} / \mathrm{rel}$ in the IL-4-induced up-regulation of the human IgE germline promoter. J . Immunol. 159, 3330-3337.

10. Shimoda, K., van Deursen, J ., Sangster, M. Y., Sarawar, S. R., Carson, R. T., Tripp, R. A., Chu, C., Quelle, F. W., Nosaka, T., Vignali, D. A. A., Doherty, P. C., Grosweld, G., Paul, W. E., and I hle, J. N. (1996) Lack of IL-4-induced Th2 response and IgE class switching in mice with disrupted Stat6 gene. Nature 380, 630- 633.

11. Berberich, I., Shu, G. L., and Clark, E. A. (1994) Cross-linking CD40 on B cells rapidly activates nuclear factor $-\kappa \mathrm{B}$. J . I mmunol. 153, 4357- 4366 .

12. Korthauer, U., Graf, D., Mages, H., Briere, F., Padayachee, M., Malcolm, S., Ugazio, A., N otarangelo, L., Levinsky, R., and Kroczek, R. (1993) Defective expression of T-cell CD40 ligand causes X-linked immunodeficiency with hyper-IgM. Nature 361, 539 541.

13. Kawabe, T., Naka, T., Yoshida, K., Tanaka, T., Fujiwara, H., Suematsu, S., Yoshida, N., Kishimoto, T., and Kikutani, H. (1994) The immune responses in CD40-deficient mice: I mpaired immunoglobulin class switching and germinal center formation. Immunity 1, 167-170.

14. Snapper, C., Zelazowski, P., Rosas, F., Kehry, M., Tian, M., Baltimore, D., and Sha, W. (1996) B cells from p50/NF- $\kappa$ B knockout mice have selective defects in proliferation, differentiation, germ-line $\mathrm{C}_{\mathrm{H}}$ transcription and Ig class switching. J . I mmunol. 156, 183-191.

15. Ren, C. L., Morio, T., Fu, S. M., and Geha, R. S. (1994) Signal transduction via CD40 involves activation of lyn kinase and phosphatidylinositol-3-kinase, and phosphorylation of phospholipase C gamma 2. J . Exp. Med. 179, 673-680.

16. Sakata, N., Patel, H. R., Terada, N., Aruffo, A., J ohnson, G. L., and Gelfand, E. W. (1995) Selective activation of c-J un kinase mitogen-activated protein kinase by CD40 on human B cells. J . Biol. Chem. 270, 30823-30828.

17. Berberich, I., Shu, G., Siebelt, F., Woodgett, J. R., Kyriakis, J. M., and Clark, E. A. (1996) Cross-linking CD40 on B cells preferentially induces stress-activated protein kinases rather than mitogen-activated protein kinases. EMBO J . 15, 92-101.

18. Sutherland, C. L., Heath, A. W., Pelech, S. L., Young, P. R., and Gold, M. R. (1996) Differential activation of the ERK, J NK, and p38 mitogen-activated protein kinases by CD40 and the B cell antigen receptor. J . I mmunol. 157, 3381-3390.

19. Salmon, R. A., Foltz, I. N., Young, P. R., and Schrader, J . W. (1997) The p38 mitogen-activated protein kinase is activated by ligation of the T or B lymphocyte antigen receptors, Fas or CD40, but suppression of kinase activity does not inhibit apoptosis induced by antigen receptors. J . I mmunol. 159, 5309-5317.

20. Craxton, A., Shu, G., Graves, J . D., Saklatvala, J ., Krebs, E. G., and Clark, E. A. (1998) P38 MAPK is required for CD40-induced gene expression and proliferation in B Iymphocytes. J . I mmunol. 161, 3225-3236

21. Cuenda, A., Rouse, J., Doza, Y. N., Meier, R., Cohen, P., Gallagher, T. F., Young, P. R., and Lee, J . C. (1995) SB 203580 is a specific inhibitor of a MAP kinase homologue which is stimulated by cellular stresses and interleukin-1. FEBS Lett. 364, 229-233.

22. Chin, T-E., Malmborg, A-C, Kristensson, K., Hinkula, J ., Wahren, B., and Borrebaeck, C. A. K. (1995) Mimicking the humoral immune response in vitro results in antigen-specific isotype switching supported by specific autol ogous $T$ helper cells: Generation of human HIV-1-neutralizing IgG monoclonal antibodies from naiive donors. Eur. J . Immunol. 25, 657- 663.

23. Raingeaud, J., Gupta, S., Rogers, J. S., Dickens, M., Han, J ., Ulevitch, R. J ., and Davis, R. J . (1995) Proinflammatory cytokines and environmental stress cause p38 mitogen-activated protein kinase activation by dual phosphorylation on tyrosine and threonine. J . Biol. Chem. 270, 7420-7426.

24. Brady, K., Fitzgerald, S., and Moynagh, P. N. (2000) Tumournecrosis-factor-receptor-associated factor 6, NF-kB-inducing kinase and I kB kinases mediate I $\mathrm{gE}$ isotype switching in response to CD40. Biochem. J . 350, 735-740.

25. Thienes, C. P., De Monte, L., Monticelli, S., Busslinger, M., Gould, H. J ., and Vercelli, D. (1997) The transcription factor B cell-specific activator protein (BSAP) enhances both IL-4- and CD40-mediated activation of the human epsilon germline promoter. J . I mmunol. 158, 5874-5882.

26. Witthuhn, B. A., Silvennoinen, O., Miura, O., Lai, K. S., Cwik, C., Liu, E. T., and Ihle, J. N. (1994) Involvement of the J ak-3 $\mathrm{J}$ anus kinase in signaling by interleukins 2 and 4 in lymphoid and myeloid cells. Nature 370, 153-157.

27. Vanden Berghe, W., Plaisance, S., Boone, E., De Bosscher, K., Schmidt, M. L., Fiers, W., and Haegeman, G. (1998) P38 and extracellular signal-regulated kinase mitogen activated protein kinase pathways are required for nuclear factor-kappaB p65 transactivation mediated by tumor necrosis factor. J. Biol. Chem. 273, 3285-3290. 